ISSN: 01416707

doi: $10.1111 /$ aje.12082

\title{
DENSITY, NEST SITE CHARACTERISTICS AND BREEDING RATES OF THE OSPREY (PANDION HALIAETUS) IN THE SOUTHERN LIMIT OF ITS RANGE IN THE WESTERN PALEARCTIC (BOA VISTA, CAPE VERDE ISLANDS)
}

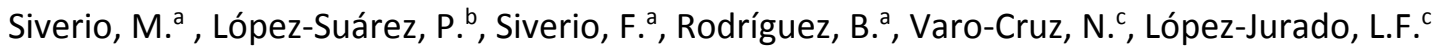 \\ ${ }^{a}$ Canary Islands' Ornithology and Natural History Group (GOHNIC), Los Barros 21, Los Realejos, Tenerife, Canary Islands, E- \\ 38410, Spain. \\ ${ }^{\mathrm{b}}$ Naturalia Capa Verde Lda, C.P. 100, Sal Rei, Boa Vista, Cape Verde. \\ c Department of Biology, University of Las Palmas de Gran Canaria, Apdo. 550, Las Palmas de Gran Canaria, Gran Canaria, Canary \\ Islands, E-35080, Spain.
}

\begin{abstract}
Between 2004 and 2007, we studied density, habitat features and breeding parameters of the osprey (Pandion haliaetus) population in Boa Vista Island (Cape Verde). A total of 79 nest structures were identified, 37 of which were occupied for at least 1 year during the study period. The osprey population ranged between 14 and 18 pairs, and the mean density and distance between neighbouring occupied nests were 2.58 pairs per $100 \mathrm{~km} 2$ and $3089 \mathrm{~m}$, respectively. Occupied nests were found to be significantly further from the coastline and roads than unoccupied nests, but the distances from villages were similar. The majority (81.1\%) of the 37 occupied nests were easily accessible to humans. Mean clutch size was 2.59, average productivity was 0.76 young/active nest, and breeding success was $58.8 \%$ [Correction added on 13 May 2013, after first online publication: the average productivity was changed from 0.72 to 0.76]. Density in Boa Vista was higher than that in other sedentary island populations in the Western Palearctic, whereas the productivity was the lowest of this region. Clutch size did not vary among Western Palearctic populations, but the differences observed in productivity were likely influenced by local factors that in Boa Vista are attributed to nest depredation by the brown-necked raven (Corvus ruficollis) and to direct human persecution.
\end{abstract}

